Engebø, A., Drevland, F., Lohne, J., Shkmot, N., and Lædre O. (2017). "Geographical Distribution of Interest and Publications on Lean Construction” In: LC3 2017 Volume II - Proceedings of the 25th Annual Conference of the International Group for Lean Construction (IGLC), Walsh, K., Sacks, R., Brilakis, I. (eds.), Heraklion, Greece, pp. 285-292. DOI: https://doi.org/10.24928/2017/0121

\title{
GEOGRAPHICAL DISTRIBUTION OF INTEREST AND PUBLICATIONS ON LEAN CONSTRUCTION
}

\author{
Atle Engebø ${ }^{1}$, Frode Drevland ${ }^{2}$, Jardar Lohne ${ }^{3}$, Nawras Shkmot $^{4}$ and Ola Lædre ${ }^{5}$
}

\begin{abstract}
It is a common view that certain countries show more interest in Lean Construction Principles than others. Some researchers within the Lean Construction community publish more and are more cited than others. The paper address the following research questions: 1) Where do those who show interest in Lean Construction come from? And 2) Is there any connection between geographical distribution of academic publications and where those who show interest in Lean Construction come from?

The research is based on empirical data collected from analysis of data traffic from the IGLC web page and the Lean Construction Blog. It also consists of a registration of what countries the authors at IGLC's annual conference and in the Lean Construction Journal come from. The analysis of the data collected validates that specific countries show more interest in lean construction than other. When publications and web-traffic were corrected for number of inhabitant's country-bycountry, the findings shows that there was a strong positive connection between the two parameters. This study could serve as a good basis for further studies on why some countries are more open to new ideas regarding construction and construction management.
\end{abstract}

Keywords: People, Culture and Change; lean expansion; mapping; web traffic.

\section{INTRODUCTION}

Established theories for analysing the life-cycle of concepts emphasise the importance for concepts reach and engage, to both the early- and late majority of their intended audience (Rogers (2002); Gartner (2007)). A concept that fails at this would suffer the consequence of disappearing into oblivion. It is therefore vital for the "concepts well-being" to reach the majority of their intended audience. Thus, a mapping of the prevalence of Lean Construction (hereafter LC) could be used to assess the concept's success in reaching the intended audience.

Pasquire and Connor (2011) evaluated whether the sources upon which the LC-theory has been based were originated from within the lean community or from outside. First, they found that the top five IGLC authors dominated and had $49 \%$ of the total citations.

1 Scientific assistant, Department of Civil and Environmental Engineering, Norwegian University of Science and Technology, Trondheim, Norway, +47 90571 902, atle.engebo@ntnu.no

2 Assistant Professor, Department of Civil and Environmental Engineering, NTNU - Norwegian University of Science and Technology, Trondheim, Norway, +47 92064 262, frode.drevland@ntnu.no

3 Research scientist, dr. art., Department of Civil and Environmental Engineering, Norwegian University of Science and Technology, Trondheim, Norway,+47934 44 930, Jardar.lohne@ntnu.no

4 Co-Founder \& CFO, Paramount Decisions, San Francisco, USA, +47 41409992, nawras@paramountdecisions.com

5 Associate Professor, dr. ing., Department of Civil and Environmental Engineering, Norwegian University of Science and Technology, Trondheim, Norway, +47 911 89 938, ola.ladre@ntnu.no 
Second, their statistical analysis showed that only $21 \%$ of the sampled papers referred were by authors who were IGLC members (sources published at IGLC conferences). They argued that the lack of internal citing within IGLC was a challenge and suggested that IGLC authors should publish more in other significant research channels with the purpose of developing the theoretical base of LC. Pasquire and Connor (2011) also examined the citation distribution of past IGLC-papers where they identified the leading figures in the development of LC theory. Since the late nineties, where the spread of LC was dependent on a few key actors, and up until today, where the field consist of academics and industry actors from many different countries, LC-principles have experienced an increased interest within both academia and the AEC-industry.

According to Sun et al. (2016), mapping the evolution of scientific fields is crucial for positive science policy and societal impact planning. Academic publishing within the field of LC is in an historical perspective a relatively new phenomenon. A mapping of the geographical distribution of LC related publications does not seem to have been carried out. An assessment of the geographical distribution of academic publication could therefore give some indicators on the prevalence of the concepts as well as research productivity of individual countries. Thus, the correlation between the general interest of LC and academic publication within national borders can indicate whether academic publishing affects public interest. The paper address the following research questions:

1. Where do those who show interest in Lean Construction come from?

2. Is there any connection between geographical distribution of academic publications and where those who show interest in Lean Construction come from?

This study examines scientific contribution by different countries with the use of data related to academic publication and general interest in LC by different countries represented with the use of web-traffic data.

\section{THEORETICAL FRAMEWORK}

\subsection{Evolution and life cycle of a scientific field}

With regards to assessing the prevalence and evolution of a scientific field, several approaches could be used. In the following paragraphs, two different approaches will be described: citation- and geographical distribution. Sun et al. (2016) explain three types of scientific maps based on citation: the first is the paper-level maps focusing on citations, co-citations etc. to create an overview of the scientific literature. The second type is journal-level maps that build maps based upon aggregated journal-journal citation relations. The third type is category-level maps based on data concerning publication category. The other approach is to examine the geographical distribution of publications based on the national belonging of either the author(s) or the institution. There are several studies conducted across different field with the purpose of uncover the geographical distribution of publications. Tutarel (2002), for example, investigated the geographical distribution of academic publications within the field of medical education. The purpose was to uncover which countries were most influential.

\subsection{Roger's theory of diffusion and Gartner's Hype Cycle}

Rogers' model describes the process of implementation of new concepts and innovations (Rogers, 2002). According to Rogers, the process of implementation might be evaluated 
through the extent of adoption. Further, he categorizes adopters as innovators, early adopters, early majority and laggards.

Another prevalent model is the Gartner's Hype Cycle, shown in Figure 2, which outlines the typical progression of an emerging technology (Gartner, 2007). The curve illustrates different stages in what referred to as the technology's maturity. The "hype" is the establishment of expectations and often overenthusiasm of the potential of the emerging technology. As the technology matures, it will encounter negative "hype" when facing critique and the technology fails to meet the overenthusiastic expectations.

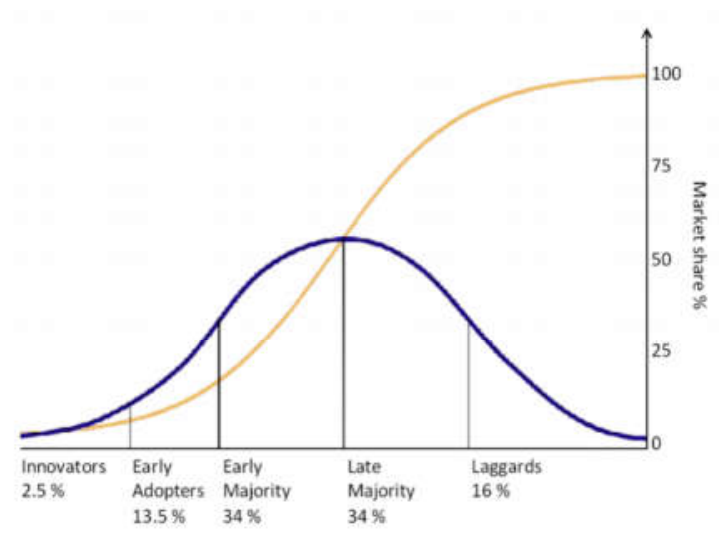

Figure 1: Diffusion of innovations

(Everett, 2016)

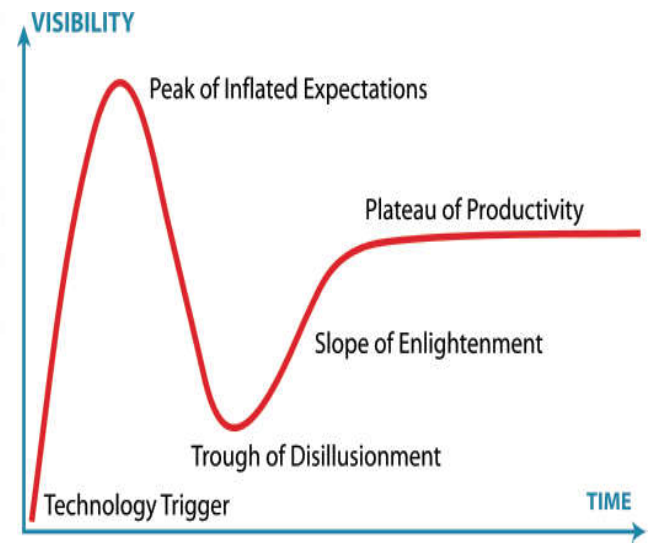

Figure 2: Gartner Hype Cycle

(Gartner, 2007)

The critical part is the next phase where the technology gets refined, adopted and either slides into what is characterized as the "slope of enlightenment" or eventually disappear into oblivion (Linden and Fenn, 2003).

\subsection{The Context of Lean Construction}

According to Howell (1999), LC is a form of production management for the construction industry. Howell concludes that LC needs to emphasis on further research in order to complete the translation to construction as adopted from lean thinking. Bertelsen (2004) investigated factors differentiating construction from manufacturing. The purpose was to identify future research areas of importance for LC. He concluded that one of the great challenges in the years to come was not to turn construction into a manufacturing process, but to keep focus on the construction process.

Naney et al. (2012) examined where LC philosophy placed on Gartner's Hype Cycle. They state that LC is an important innovation for the industry. Further, they emphasise that the benefits and potential of the innovation itself is not enough to push innovation to adoption. The LC community needs to understand what barriers exist and further develop strategies to remove them. The paper concludes that innovations need key influencers and a contextual environment that promotes the necessary changes. LC has to address the barriers in order to move from the phase of early adoption to reach the early majority.

Nesensohn et al. (2014) offers a framework for assessing LC maturity and describes how to assess the current level of LC maturity in organizations. The purpose is to provide guidance for organisations that want to implement LC. They state that the industry increasingly implements lean construction principles. Their proposed framework contributes in the process of improving the LC capability in organisations.

Wandahl (2014) examined the implementation of LC in Denmark, addressing how widespread LC actually was. The findings indicated that 3 out of 4 in the Danish 
construction industry did not know of LC. Secondly, it was addressed how Lean Construction was implemented. The findings confirmed that more than $25 \%$ applied LC elements partly or contrary to what was identified as best practice. The author concludes that different barriers exist to overcome when implementing LC and that an understanding of such barriers is highly relevant for the future success and development of LC.

Simonsen et al. (2014) analysed LC as a management concept in order to identify whether it was a fad or an enduring concept. In the context of concept life-cycle, LC has experienced both rise and fall in interest. The paper examined the case of Denmark and the authors suggested that it would be interesting to see whether LC will follow the same path in other national arenas.

\section{Methodology}

To address the research questions, a suitable sampling method and size had to be chosen. To measure interest, we chose to accredit academic contributions by country as a quantitative measure of interest. Academic contribution was supplemented with data about the general interest related to the field of LC. Web-traffic in form of number of viewing-session was chosen as an indicator of public interest. The data spans from four primary sources; 1) IGLC proceedings, 2) Lean Construction Journal, 3) viewer-traffic of the IGLC web-page and 4) viewer-traffic of the Lean Construction blog.

First, each abstract of papers in the IGLC proceedings were reviewed with the aim of extracting authors' name and institutional belonging. Regarding the analysis of data, the following approach was used; each author contributes with one count in favour of the nationality of their institutional belonging. The practice of crediting nationality based on institutional belonging instead of authors primary nationality was chosen on basis of academia being characterized by a high degree of internationalization. The following counting system was applied: each author in the list of authors contributes with one "publication-count" to their respective institutions. For example; Pasquire and Connor (2011) contributed with one count for each, so then United Kingdom got two counts. The same approach was adopted when data from the Lean Construction Journal was collected. The data collection included the proceedings from IGLC 4 (1996) to IGLC 24 (2016), primarily since these were available online. From the journal, the data collection includes every publication from Volume 1 issue 1 (2004) to the Volume 13 issue 1 (2016).

All papers from the proceedings and the journal database were registered and ranked in two categories based on country of origin: Publications and authors per $10^{6}$ inhabitants. The use of quantitative data in form of data traffic are categorized as webometrics, which is an emerging research field emphasising the use of various types of data to study the Web (Vaughan and Yang, 2013). The data from the IGLC web page and the Lean Construction Blog was gathered with the use of Google Analytics. The final dataset was tested for potential correlations by determine the Pearson $r$ correlation coefficient. In order to linearize the relationship between the variables we applied a logarithmic transformation. This was considered convenient in order to eliminate skewness created by large values in the dataset. Countries with either zero publications or sessions are excluded from the graphical presentation of the findings as well as for the Pearson $r$ calculation. Therefore, the representation only consist of countries with both academic publishing and web traffic.

The study is limited to the use of four different sources relevant to LC. This was considered a convenient sampling-size, but the authors acknowledge they are not the only LC-related channels. Another limitation is that the data in the IGLC proceedings only include institutional affiliation of the authors/ contributors. The result is therefore that 
authors do not necessarily represent their country of birth, but the country of their institutional belonging.

A potential source of error is the process of categorizing authors and publications, particularly for publications with several contributors from different institutional belonging. Another source of error related to the measurement of general interest, is that of language. While academic channels are mostly standardized on using English, the same cannot be said for practice. Web-traffic are measured as total web-traffic to the examined web sites, therefore it does not take in to account phenomena's such as bounce-rate (singlepage visit) and unique visitors. Unique visitors are for example difficult to measure, if the web-user have deleted web-cookies between two sessions, Google will count it as two unique visitors.

\section{RESULTS}

The publications spans from IGLC 4 (1996) to IGLC 24 (2016), including 1310 IGLCproceedings papers and 72 journal articles. The data-traffic includes 101793 unique internet-sessions on the web-sites of IGLC.net and the Lean Construction Blog. Table 1 shows the top 20 countries, by number of papers ("publication-counts", not number of unique papers, ref. methodology p.3). Table 1 compares the data on the number of authors, papers- and sessions as well as the data on number of papers, authors and web-sessions per 10 million inhabitants' country-by-country.

Table 1: top 20 countries, by no. of papers

\begin{tabular}{llllllll}
\hline & Country & $\begin{array}{l}\text { No. of } \\
\text { authors }\end{array}$ & $\begin{array}{l}\text { No. of } \\
\text { papers }\end{array}$ & $\begin{array}{l}\text { No. of } \\
\text { Sessions }\end{array}$ & $\begin{array}{l}\text { Papers / 10 } \\
\text { millions }\end{array}$ & $\begin{array}{l}\text { Authors/ 10 } \\
\text { millions }\end{array}$ & $\begin{array}{l}\text { Sessions/ 10 } \\
\text { million }\end{array}$ \\
\hline 1. & United States & 1038 & 453 & 24239 & 14,1 & 32,3 & 754 \\
\hline 2. & Brazil & 619 & 224 & 8585 & 11,0 & 30,3 & 420 \\
\hline 3. & UK & 527 & 223 & 8566 & 34,8 & 82,2 & 1337 \\
\hline 4. & Lebanon & 69 & 222 & 1162 & 355,9 & 110,6 & 1863 \\
\hline $\mathbf{5 .}$ & Finland & 161 & 84 & 1696 & 153,4 & 294,0 & 3097 \\
\hline $\mathbf{6 .}$ & Norway & 207 & 80 & 6281 & 153,6 & 397,5 & 12061 \\
\hline $\mathbf{7 .}$ & Chile & 179 & 72 & 2040 & 41,1 & 102,2 & 1165 \\
\hline $\mathbf{8 .}$ & Sweden & 122 & 57 & 1429 & 58,2 & 124,5 & 1458 \\
\hline $\mathbf{9 .}$ & Denmark & 94 & 54 & 1337 & 96,7 & 168,4 & 2395 \\
\hline $\mathbf{1 0 .}$ & Germany & 105 & 44 & 5926 & 5,4 & 13,0 & 733 \\
\hline $\mathbf{1 1 .}$ & Australia & 94 & 41 & 2332 & 18,0 & 41,3 & 1025 \\
\hline $\mathbf{1 2 .}$ & Israel & 74 & 32 & 593 & 39,1 & 90,5 & 725 \\
\hline $\mathbf{1 3 .}$ & New Zealand & 48 & 26 & 1372 & 58,1 & 107,3 & 3066 \\
\hline $\mathbf{1 4 .}$ & Peru & 35 & 19 & 4011 & 6,2 & 11,4 & 1305 \\
\hline $\mathbf{1 5 .}$ & Netherlands & 24 & 17 & 1504 & 10,0 & 14,1 & 884 \\
\hline $\mathbf{1 6 .}$ & Taiwan & 25 & 16 & 0 & 6,8 & 10,7 & 0 \\
\hline $\mathbf{1 7 .}$ & South Korea & 47 & 16 & 347 & 3,1 & 9,2 & 68 \\
\hline $\mathbf{1 8 .}$ & Singapore & 33 & 15 & 1160 & 25,9 & 57,1 & 2006 \\
\hline $\mathbf{1 9 .}$ & Portugal & 27 & 13 & 446 & 12,0 & 24,9 & 412 \\
\hline $\mathbf{2 0 .}$ & Colombia & 34 & 10 & 1158 & 2,1 & 7,2 & 245 \\
\hline & & & & & & \\
\hline
\end{tabular}

Figure 3 show the geographical distribution of publications per 10,000,000 inhabitants. 48 different countries had published academic content on the subject of LC, but in figure 3 all countries with a publishing factor below 0.09 are - for space reasons - excluded. Figure 3 uses a temperature diverging colour-scale to differentiate countries by publications. 


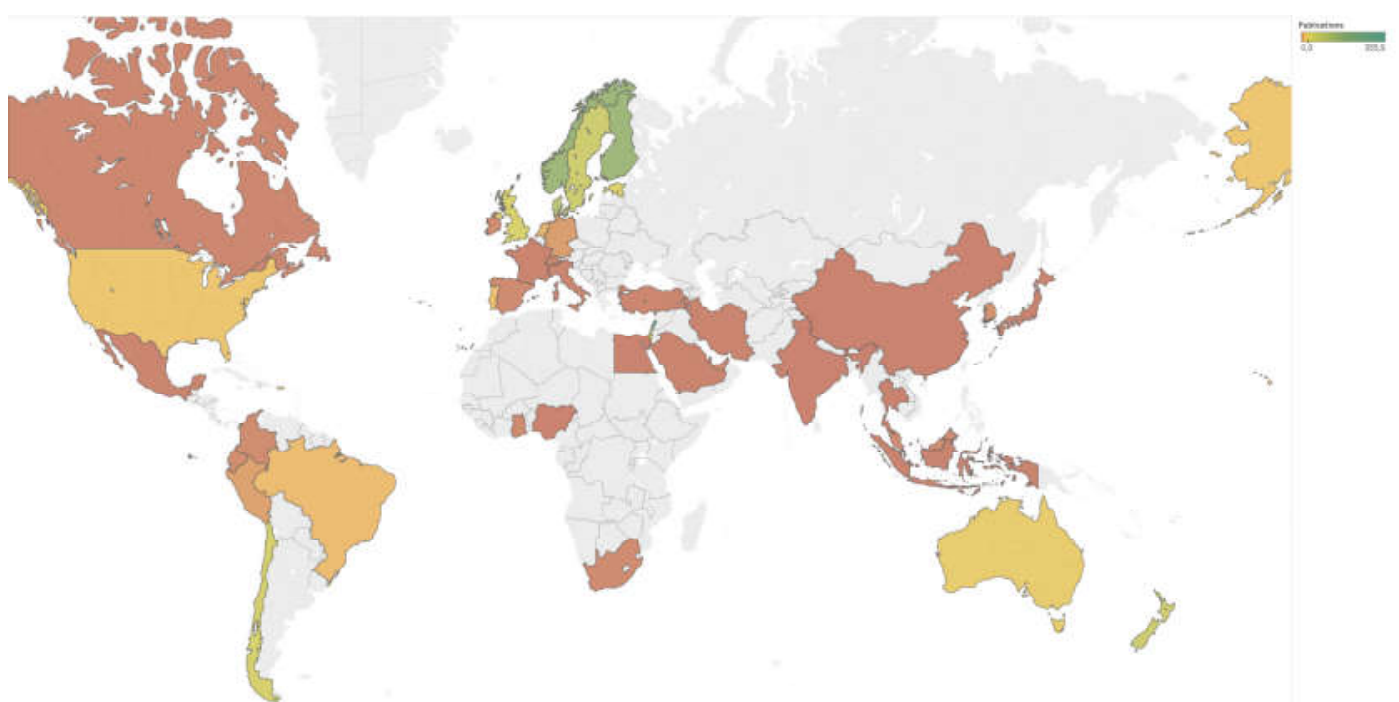

Figure 3: Geographical distribution of publications (temperature diverging colour scale)

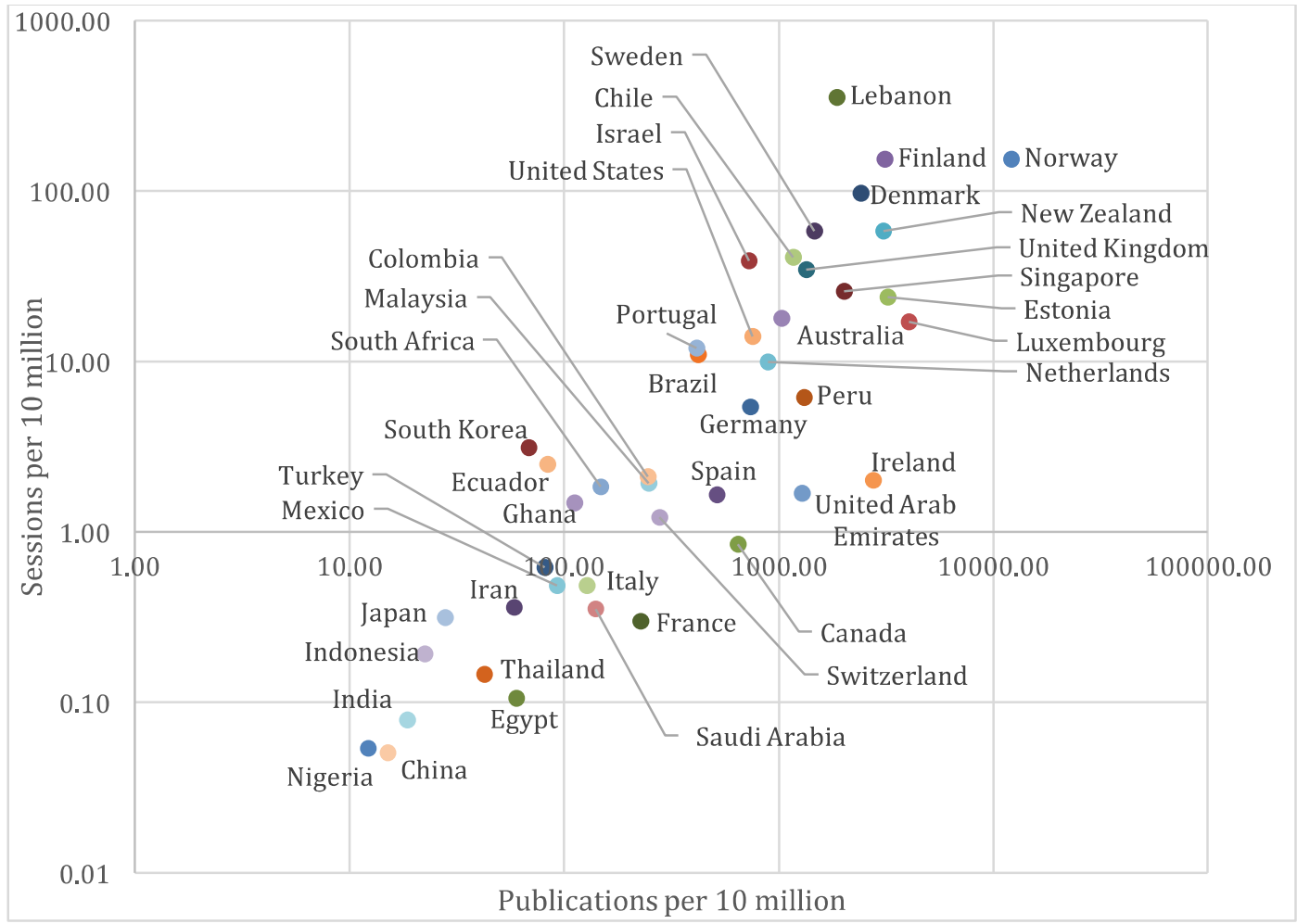

Figure 4: Log-10 representation of countries, by publications and sessions per 10 million inhabitants

Figure 4 show the distribution of all 48 countries with publications per 10,000,000 inhabitants on the $\mathrm{x}$-axis and sessions per 10,000,000 inhabitants on $\mathrm{y}$-axis. In order to present the data, we used a log-10 scale for both the $\mathrm{Y}$-and the $\mathrm{X}$-axis. This was necessary because of the large range of values.

The correlation between the parameters is significant, as the Pearson $\mathrm{r}$ correlation coefficient between the variables Log (publications) and Log (sessions) was calculated to 
be 0.87 . As publications per 10 million increase, sessions per 10 million tend to increase, so it is a positive association.

\section{DISCUSSION}

The paper has addressed the following research questions: "Where do those who show interest in Lean Construction come from?" and "Is there any connection between geographical distribution of academic publications and where those who show interest in Lean Construction come from?". Our investigation spans from 1996-2016 with the total of 1382 examined publications and above 101793 unique web sessions.

Both in total numbers of publications and total number of authors the United States, United Kingdom and Brazil excels with 64.91 percent of the total publications. When we adjust the numbers with regards to for national populations, the tables turn. After the adjustment, the Nordic countries of Finland, Sweden, Denmark and Norway as well as the Middle East countries Israel and Lebanon excel. Interestingly, more than 48 different countries have showed interest in LC in form of academic publishing.

When publications and sessions were adjusted for number of inhabitant's country-bycountry, some interesting results emerged (see figure 4). There is a cluster of 11 countries that are scoring high on both sessions- and publications and a cluster of seven countries right below. Six countries are found on both the top ten lists of sessions- and publications per 10 million inhabitants: Sweden, Norway, New Zealand, Lebanon, Finland and Denmark. The four countries only represented on one top list for publications were United Kingdom, Liechtenstein, Israel and Chile. Singapore, Luxembourg, Ireland and Estonia are only represented on one top list for web-sessions. The results shows that there was a strong positive correlation $(\mathrm{r}=0.87)$ between academic publishing and sessions, but the data likewise presented cases where no such connection was observable. For example, on websessions Russia place seventh, still no Russian publications were registered. This was as well the case with the following countries: Qatar, Hong Kong, Costa Rica, Panama, Russia, Austria, Kazakhstan, Argentina, Belgium, Poland, Philippines and Kenya.The research also reveals that countries such as Japan and France, which are perceived to have traditions within Lean production failed to make the list of influential contributors to LC.

\section{CONCLUSION}

Geographical distribution of publications and web-traffic in some of the leading Lean Construction contribution channels (IGLC, LCI and LCB) show that 48 different countries have showed interest in LC- principles. Publishing of scientific results from a variety of academic institution should be seen as an indicator that the LC concept has grasped a broader audience. The positive association between web sessions and academic publishing does not prove causality, but indicate a general relationship between the two variables. Countries scoring high on academic contribution tended to score high on web searches. On a general basis, the combination of a relatively small population and academic institutions emphasising on LC-related research seems to provide some sort of viral effect on the countries interest in LC. Thus, for the LC as an own field to survive, the need to both document experiences and develop theories, and disseminate them. The correlation between the general interest of LC and academic publication within national borders is significant. Thus, if we lay emphasis on the Roger's model (Rogers, 2002), more educational institutions need to show interest in LC to sustain the process of spreading LC principles. 


\subsection{Further work}

This study could serve as a foundation for further research aimed at uncovering why some countries are showing greater interest in LC than other. Lean Construction has a relatively brief history of research and publishing. The Lean Construction Journal and the IGLCproceedings are important research channels, but LC related publications are also published through other channels. A suggestion is to include other relevant channels.

\section{REFERENCES}

Bertelsen, S. 2004. Lean Construction: Where are we and how to proceed. Lean Construction Journal, 1, 46-69.

Everett, R. 2016. Diffusion of innovations. In: INNOVATIONS, D. O. (ed.). https://en.wikipedia.org: Based on Rogers, E. (1962) Diffusion of innovations. Free Press, London, NY, USA.

Gartner, I. 2007. Gartner Research's Hype Cycle diagram. In: DIAGRAM, G. R. S. H. C. (ed.). https://commons.wikimedia.org.

Howell, G. A. What is lean construction-1999. Proceedings IGLC, 1999. Citeseer, 1.

Linden, A. \& Fenn, J. 2003. Understanding Gartner's hype cycles. Strategic Analysis Report $N^{\circ} R-20-1971$. Gartner, Inc.

Naney, D., Goser, C. \& Azambuja, M. Accelerating the Adoption of Lean Thinking in the Construction Industry. In: TOMMELEIN, I. D. \& PASQUIRE, C. L., eds. 20th Annual Conference of the International Group for Lean Construction, 2012/07/18 2012 San Diego, USA.

Nesensohn, C., Bryde, D., Ochieng, E., Fearon, D. \& Hackett, V. Assessing Lean Construction Maturity. In: KALSAAS, B. T., KOSKELA, L. \& SAURIN, T. A., eds. 22nd Annual Conference of the International Group for Lean Construction, 2014/06/25 2014 Oslo, Norway. 1157-1168.

Pasquire, C. \& Connor, P. Where does the Theory Informing the International Group for Lean Construction Come From? In: ROOKE, J. \& DAVE, B., eds. 19th Annual Conference of the International Group for Lean Construction, 2011/07/13 2011 Lima, Peru.

Rogers, E. M. 2002. Diffusion of preventive innovations. Addictive behaviors, 27, 989-993.

Simonsen, R., Thyssen, M. H. \& Sander, D. Is Lean Construction Another Fading Management Concept? In:KALSAAS, B. T., KOSKELA, L. \& SAURIN, T. A., eds. 22nd Annual Conference of the International Group for Lean Construction, 2014/06/25 2014 Oslo, Norway. 85-96.

Sun, X., Ding, K. \& Lin, Y. 2016. Mapping the evolution of scientific fields based on crossfield authors. Journal of Informetrics, 10, 750-761.

Tutarel, O. 2002. Geographical distribution of publications in the field of medical education. BMC Medical Education, 2, 3.

Vaughan, L. \& Yang, R. 2013. Web traffic and organization performance measures: Relationships and data sources examined. Journal of Informetrics, 7, 699-711.

Wandahl, S. Lean Construction with or without Lean - Challenges of Implementing Lean Construction. In: KALSAAS, B. T., KOSKELA, L. \& SAURIN, T. A., eds. 22nd Annual Conference of the International Group for Lean Construction, 2014/06/25 2014 Oslo, Norway. 97-108. 